\section{Two-step removal of a migrated double-layered stent through a neoplastic stenosis using another double-layered stent and endoloops}

Double layered self-expanding metal stents (SEMSs) are an effective treatment when placed across the gastroesophageal junction for malignant esophageal obstructions. The double layer provides effective prevention of stent migration, with the advantages of a covered stent [1]. However, should the stent migrate, the double layer makes endoscopic removal more difficult.

A 79-year-old man with symptoms of dysphagia was diagnosed as having a distal esophageal neoplasm during an esophagogastroscopy performed in another hos- pital. Biopsies confirmed a diagnosis of adenocarcinoma. Because of his persistent dysphagia it was decided to place a double-layered SEMS before he started chemotherapy.

After the first cycle of chemotherapy, the patient presented to our hospital with symptoms of aphagia. Gastroscopy was performed, which revealed a malignant stricture that was preventing passage of the endoscope. An abdominal radiograph showed a migrated double-layered stent within the gastric chamber. After explaining to the patient and his family members, we decided to place a new $100 \times 18-\mathrm{mm}$ double-layered SEMS under fluoroscopic control.

The patient showed an improvement in his symptoms and remained in the hospital for 48 hours on liquid feeding. Subsequently he underwent a repeat endoscopy, at which the double-layered SEMS was shown to be fully expanded ( $\bullet$ Fig. 1 a). The new stent allowed the endoscope to be passed into the stomach, where the migrated double-layered SEMS could be seen ( $\bullet$ Fig. 1 b).

Because we knew that the inner diameter of the new esophageal stent was less than the size of the ends of the migrated stent, we decided to use endoloops (Polyloop, HX-400U-30; Olympus) to reduce the radial size of the migrated stent. We placed four endoloops along the stent body, reducing considerably its size ( $\bullet$ Fig. 1 c, d). We then used a grasping forceps (Polygrab
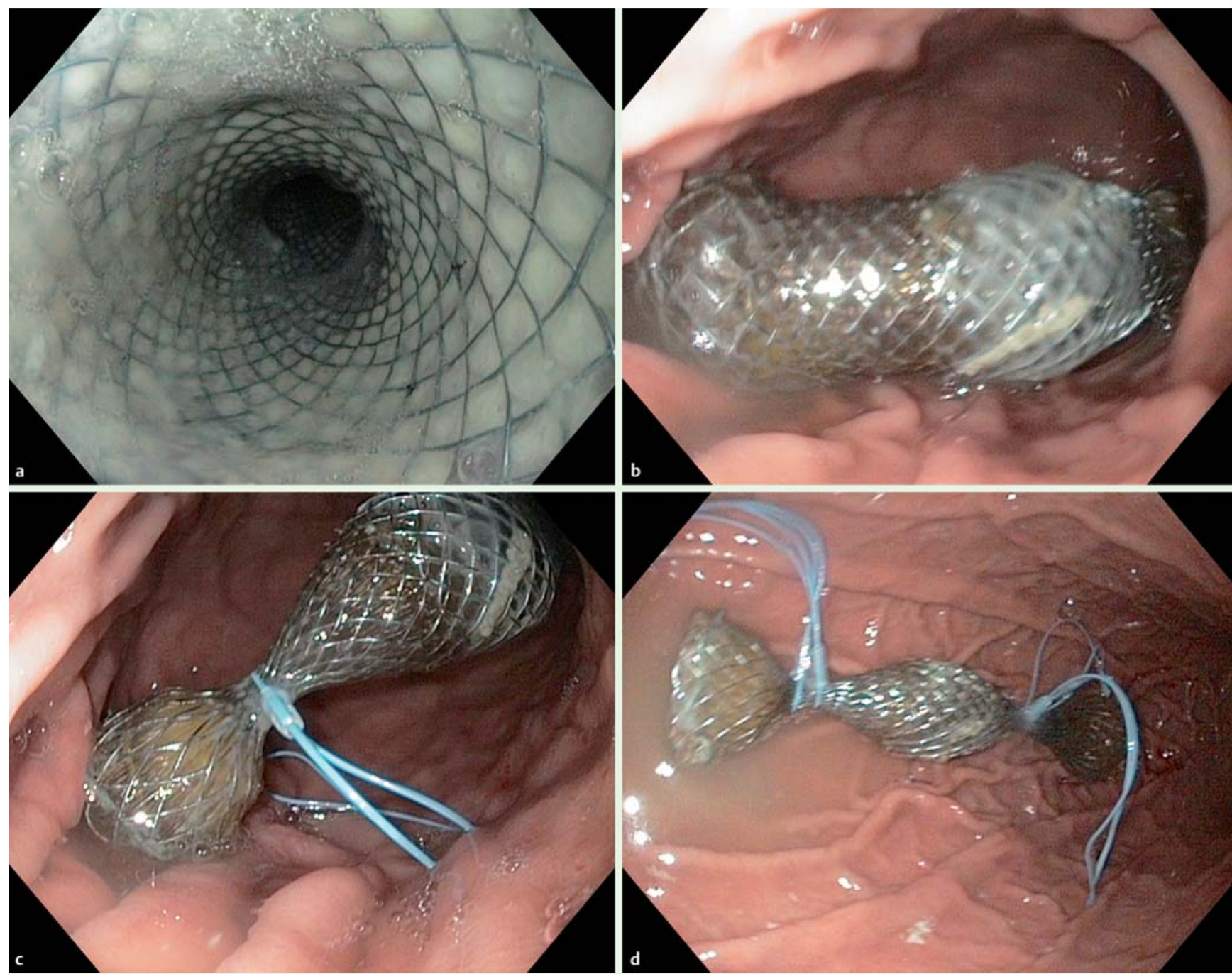

Fig. 1 Endoscopic images in a 79-year-old man with esophageal adenocarcinoma and a migrated esophageal stent showing: a the fully expanded new doublelayered self-expanding metal stent (SEMS) in position; $\mathbf{b}$ the migrated double-layered SEMS inside the stomach; $\mathbf{c}$ endoloops being placed around the body of the migrated stent; $\mathbf{d}$ the migrated stent with significantly reduced size following endoloop placement. 


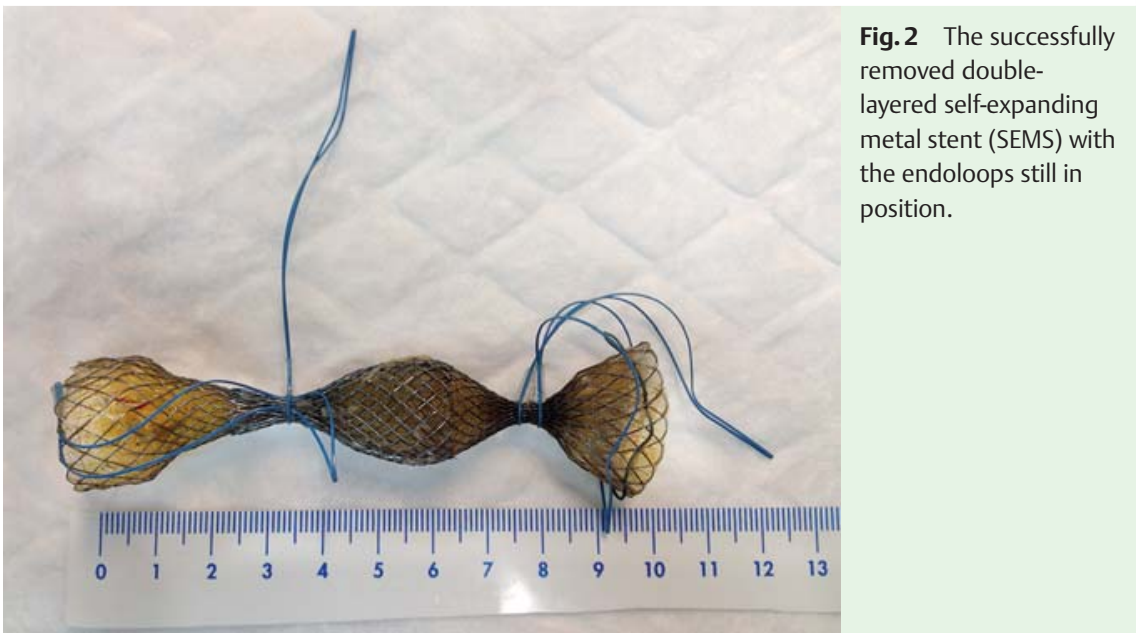

Tripod, FG-600U; Olympus) to take hold of the proximal end of the stent, which was removed without any difficulty gaining traction ( $\bullet$ Fig. 2 ).

The use of endoloops to facilitate removal of a migrated SEMS has been described in a few cases [2 -5]. The placement of a new stent and the use of endoloops can be of great help in such cases with a migrated prosthesis where the stenosis does not allow passage of the endoscope.

Endoscopy_UCTN_Code_TTT_1AO_2AZ

\section{Competing interests: None}

\section{F. Sábado, J. Pitarch, A. Bolós, \\ B. Castelló, A. Peris}

Department of Gastroenterology, Consorcio Hospitalario Provincial de Castellón, Castellón de la Plana, Spain

\section{References}

1 Kim MD, Park SB, Kang DH et al. Double layered self-expanding metal stents for malignant esophageal obstruction, especially across the gastroesophageal junction. World J Gastroenterol 2012; 18: 3732 -3727
2 Seitz U, Thonke F, Bohnacker $S$ et al. Endoscopic extraction of a covered esophageal Z-stent with the aid of endoloops. Endoscopy $1998 ; 30$ : S91

3 De Ronde T, Martinet JP, Melange M. Easy removal of migrated self-expanding esophageal metal stent using an endoloop device. Gastrointest Endosc 2000; 52: 125-127

$4 \mathrm{An} \mathrm{HJ}$, Lee HY, Kim BW et al. Endoscopic removal of a migrated esophageal self-expandable metal stent after compression with detachable snares through an intact esophageal stent. Gastrointest Endosc 2010; 71: 205-220

5 Molina-Infante J, Fernandez-Bermejo M, Perez-Gallardo B. Removal of a migrated covered metallic stent through an esophageal stricture, with multiple endoloops. Endoscopy 2010; 42 (Suppl. 02): E268 -E269

\section{Bibliography}

Dol http://dx.doi.org/

10.1055/s-0033-1344592

Endoscopy 2013; 45: E271-E272

(c) Georg Thieme Verlag KG

Stuttgart · New York

ISSN 0013-726X

\section{Corresponding author}

\section{F. Sábado, MD}

Department of Gastroenterology Consorcio Hospitalario Provincial de Castellón Av Doctor Clara

19 Castellón de la Plana 12002

Spain

Fax: +34-964-354301

fersabado@hotmail.com 